\title{
Energy Sinks for Lee Waves in Shear Flow
}

\author{
ERIC KUNZE \\ Northwest Research Associates, Redmond, Washington \\ REN-CHIEH LIEN \\ Applied Physics Laboratory, University of Washington, Seattle, Washington
}

(Manuscript received 2 March 2019, in final form 6 August 2019)

\begin{abstract}
Microstructure measurements in Drake Passage and on the flanks of Kerguelen Plateau find turbulent dissipation rates $\varepsilon$ on average factors of 2-3 smaller than linear lee-wave generation predictions, as well as a factor of 3 smaller than the predictions of a well-established parameterization based on finescale shear and strain. Here, the possibility that these discrepancies are a result of conservation of wave action $E / \omega_{L}=E /|k U|$ is explored. Conservation of wave action will transfer a fraction of the lee-wave radiation back to the mean flow if the waves encounter weakening currents $U$, where the intrinsic or Lagrangian frequency $\omega_{L}=|k U| \downarrow|f|$ and $k$ the along-stream horizontal wavenumber, where $k U \equiv \mathbf{k} \cdot \mathbf{V}$. The dissipative fraction of power that is lost to turbulence depends on the Doppler shift of the intrinsic frequency between generation and breaking, hence on the topographic height spectrum and bandwidth $N / f$. The partition between dissipation and loss to the mean flow is quantified for typical topographic height spectral shapes and $N / f$ ratios found in the abyssal ocean under the assumption that blocking is local in wavenumber. Although some fraction of lee-wave generation is always dissipated in a rotating fluid, lee waves are not as large a sink for balanced energy or as large a source for turbulence as previously suggested. The dissipative fraction is $0.44-0.56$ for topographic spectral slopes and buoyancy frequencies typical of the deep Southern Ocean, insensitive to flow speed $U$ and topographic splitting. Lee waves are also an important mechanism for redistributing balanced energy within their generating bottom current.
\end{abstract}

\section{Introduction}

Roughly $1 \mathrm{TW}$ is input to the balanced ocean circulation and eddy fields by wind work (Wunsch 1998; von Storch et al. 2007; Scott and Xu 2009; Ferrari and Wunsch 2009). But how this power is dissipated to maintain a steady state for balanced flow-as needed to break the perpetual motion cycle of gyre-scale flows destabilizing into Rossby-scale eddies only to inversely cascade energy back to the basin scale-remains uncertain. Suggested sinks include (i) bottom drag, which appears to account for less than $25 \%$ (Arbic and Flierl 2004; Sen et al. 2008; Arbic et al. 2009), though form drag associated with topographic blocking may be larger (Klymak 2018); (ii) interior loss of balance to spontaneous and stimulated internal gravity wave generation (Polzin 2010; Plougonven and Zhang 2014; Shakespeare and Taylor 2013, 2014, 2015; Shakespeare

\footnotetext{
Corresponding author: Eric Kunze, kunze@nwra.com
}

2019), which appears to be an even smaller fraction (Nagai et al. 2015), though this depends on the waves being reabsorbed before dissipating (Shakespeare and Hogg 2017); (iii) surface-layer submesoscale instabilities cascading to dissipation (Molemaker et al. 2010; D'Asaro et al. 2011; Nikurashin et al. 2013); and (iv) wind-work suppression (Ferrari and Wunsch 2009). One of the largest predicted pathways to dissipation at $0.2-0.75 \mathrm{TW}$ is through (v) topographically generated internal lee waves (Scott et al. 2011; Nikurashin and Ferrari 2011; Wright et al. 2014; Melet et al. 2014; Trossman et al. 2016; Yang et al. 2018, 2019). Wright et al. obtained the highest of these estimates by correcting for low abyssal currents in HYCOM, but it had \pm 0.2 -TW uncertainties associated with the buoyancy frequency climatology, as well as unquantified uncertainties associated with their bottom velocity product and theoretical assumptions. Lee waves are expected to be a major energy sink for Antarctic Circumpolar Currents in the Southern 
Ocean (ACC; Gille 1997), which accounts for $50 \%$ of the global wind work.

Internal lee waves are generated by flow $U$ over topography $h(x, y)$ (Bell 1975; Baines 1995). Their intrinsic phase speed is equal and opposite to the flow $\omega_{L} / k=-U$ so that they are stationary in an Eulerian frame $\left(\omega_{E}=0\right)$, where $\omega_{L}=|k U|=|\mathbf{k} \cdot \mathbf{V}|$ is the intrinsic or Lagrangian frequency following the water, $\omega_{E}$ the Eulerian frequency in a fixed frame, and $k$ the along-stream topographic wavenumber. Free internal lee waves only exist for $|f|<|k U|<N$ because they are internal gravity waves.

However, recent microstructure measurements in the Southern Ocean find turbulent dissipation rates $\varepsilon$ as much as an order of magnitude below lee-wave generation predictions (Sheen et al. 2013; Waterman et al. 2013, 2014; Cusack et al. 2017). While the predictions are in doubt because they are based on 1D topography $h(x)$ and neglect nonlinear topographic blocking and splitting by lower-wavenumber topography (Nikurashin et al. 2014; Trossman et al. 2015, 2016; Klymak 2018), observations in Drake Passage and on the north flank of Kerguelen Plateau find elevated internal-wave shear variance and turbulent dissipation rates associated with the deep-reaching Subantarctic, Polar, and South Antarctic Circumpolar Fronts (St. Laurent et al. 2012; Brearley et al. 2013; Waterman et al. 2013; Sheen et al. 2013), qualitatively consistent with interaction of these jets with topography generating upward-propagating internal lee waves which break to produce turbulence in the water column. Quantitative comparisons find that measured dissipation is only a fraction of the estimated upward lee-wave energy-flux (Bell 1975; Nikurashin and Ferrari 2010a; Cusack et al. 2017). Within 500 meters above bottom (mab), Waterman et al. (2013) reported similar dissipation rates inside and outside regions of high predicted lee-wave generation. Elevated dissipation rates were found at 1000-1500 mab in regions of higher predicted leewave generation, pointing to transmission of bottomgenerated energy aloft by lee waves. Brearley et al. (2013) reported that water column dissipation rates were better-correlated with near-bottom than nearsurface flows, suggesting the near-bottom flow field is not barotropic equivalent, that is, not coupled to the surface flow. The dissipation in their mooring measurements near a Scotia Sea undersea hill was due to a few large events and only $20 \%$ of the predicted leewave radiation, though this may be partially due to advection and radiation away from the mooring site. Cusack et al. (2017) described a lee wave downstream of a Shackleton Fracture Zone ridge with an upward energy-flux of $\sim 1 \mathrm{~W} \mathrm{~m}^{-2}$. They inferred vertically integrated dissipation rates two orders of magnitude smaller.

Directly measured microstructure dissipation rates also fall below inferences based on a finescale shear-andstrain parameterization (Gregg and Kunze 1991; Polzin et al. 1995; Gregg et al. 2003; Naveira Garabato et al. 2004a,b; Kunze et al. 2006; Wu et al. 2011; Whalen et al. 2012; Ijichi and Hibiya 2017) in Antarctic Circumpolar Currents by factors of $5 \pm 0.5$ in Drake Passage and on the north flank of Kerguelen Plateau (Waterman et al. 2013, 2014) and factors of 2-3 south of Australia (Takahashi and Hibiya 2019). Brearley et al. (2013) reported that the finescale parameterization was consistent with lee-wave generation predictions. Kunze (2017) inferred integrated dissipations of less than $0.03 \mathrm{TW}$ south of $40^{\circ} \mathrm{S}$ with a strain-based finescale parameterization applied to CTD casts, a factor of 3-10 below the 0.1-0.3-TW dissipation proposed for lee waves in the Southern Ocean (Scott et al. 2011; Nikurashin and Ferrari 2011; Melet et al. 2014; Wright et al. 2014). Direct microstructure measurements (e.g., St. Laurent et al. 2012; Waterman et al. 2014) find maximum average nearbottom dissipation rates less than $10^{-8} \mathrm{~W} \mathrm{~kg}^{-1}$. That microstructure measurements fall below both lee-wave generation and finescale parameterization predictions suggests that lee-wave power is finding another sink.

Waterman et al. (2014) showed that sites of this discrepancy are characterized by (i) bottom-intensified flows $U \sim 0.2 \mathrm{~m} \mathrm{~s}^{-1}$, (ii) moderate topographic roughness $h_{\text {rms }} \sim O(100) \mathrm{m}$, (iii) lower-than-typical shear/strain variance ratio $R_{\omega}=\left\langle V_{z}^{2}\right\rangle /\left(N^{2}\left\langle\xi_{z}^{2}\right\rangle\right)=\left(\omega_{L}^{2}+f^{2}\right) /\left(\omega_{L}^{2}-f^{2}\right)$ signifying higher-than-typical intrinsic frequencies $\omega_{L}$, (iv) upward energy propagation as inferred both from clockwise-rotating-with-depth shear and downward phase propagation, and (v) narrowband vertical wavelengths $\sim O(100) \mathrm{m} \sim O(U / N)$ [although Sheen et al. (2013) reported no well-defined spectral peak in shear or strain]. Features iii-v are consistent with expectations for lee-wave generation in the continuum band $f \ll|k U| \ll N$ radiating aloft (e.g., Nikurashin and Ferrari 2010a).

Trossman et al. (2015) revisited this comparison, contrasting the microstructure measurements with the Garner (2005) model, which neglects rotation, horizontal propagation, horizontal advection, boundary reflections, and wave-wave and wave-mean flow interactions. They reported consistency with topographic blocking (inverse topographic Froude number or steepness parameter $N h / U>0.7$ ) below 1000 mab. Topographic blocking suppresses flow that is a distance $\sim U / N$ below ridge crests for 1D topography and forces the flow around, rather than over, 2D obstacles 
to shed vortices depending on their geometry (Baines 1995). Topographic blocking has thus been argued to induce saturation of lee-wave generation such that the effective topographic height $h_{\text {eff }}$ does not exceed $\sim 0.7 U / N$; more generally $m h_{\text {eff }} \sim 0.7$ where $m$ is the lee-wave vertical wavenumber. Nikurashin et al. (2014) reported saturation for $N h / U>0.4$ for superinertial 2D topography $h(x, y)$. Trossman et al. reported consistency with observations in the bottom few hundred meters but order-of-magnitude overprediction by the Garner model higher in the water column, consistent with Waterman et al. (2014).

A number of explanations for the suppression of turbulent dissipation at $\sim 1000-1500$ mab reported by Waterman et al. (2014) have been put forward:

(i) LADCP and CTD instrument noise at low $N$ (Kunze et al. 2006; Kunze 2017), although Waterman et al. (2014) ruled out instrumental problems on the north flank of Kerguelen Plateau, as well as issues with quantifying turbulent dissipation rates $\varepsilon$ from microstructure measurements and the finescale parameterization.

(ii) Biased or undersampling of a highly heterogeneous turbulence field (Klymak 2018).

(iii) Poor representation of near-bottom flows or smallscale bathymetry (Trossman et al. 2015, 2016). Bathymetry on the scales that generate lee waves in the ocean is not resolved by global datasets such as Smith and Sandwell (1997) (Kunze and Llewellyn Smith 2004; Nikurashin and Ferrari 2010a), so must be treated statistically (Goff and Jordan 1988; Goff 2010; Goff and Arbic 2010). Lee-wave generation is reduced both for $2 \mathrm{D}$ topography and by saturation due to topographic blocking for $N h / U>0.7$ in 1D $h(x)$ (Baines 1995; Garner 2005; Nikurashin et al. 2014; Klymak 2018 ) and $>0.4$ in $2 \mathrm{D} h(x, y)$ (Nikurashin et al. 2014). Treating the bottom boundary condition as linear, with the lee-wave generation band $|f / U|<|k|<|N / U|$ unaffected by blocking and splitting at lower-wavenumber topography, may either under- or overestimate lee-wave generation (Nikurashin et al. 2014; Klymak 2018) depending on details of the bathymetry that are not available from the spectral representations, for example, with blocking, fields of hollows will have lower generation than fields of hills.

(iv) The cascade is short-circuited near the bottom, though this would produce higher near-bottom dissipation rates that are not observed (Waterman et al. 2013). (v) Lee-wave energy is swept downstream to dissipate at a location other than the generation site (Zheng and Nikurashin 2019), though this was not the case in the freely drifting profiling float data of Cusack et al. (2017).

(vi) Wave-wave interactions between lee waves and the background wave field drains energy into free waves that can escape the currents (Kunze et al. 1995; M. Claret 2019, personal communication).

(vii) Either 1) a narrowband lee-wave signal with $\omega_{L}=$ $f(k)=g(m)$, where $k$ is the along-stream topographic horizontal wavenumber and $m$ the vertical wavenumber, or 2) the narrow abyssal frequency bandwidth $N / f \sim 3-4$ do not lend themselves to as efficient an energy cascade as the broadband canonical internal-wave field. This might explain the finescale parameterization overestimation of turbulent dissipation but not lee-wave power generation overestimation.

(viii) Conservation of wave action $E /|k U|$ (Bretherton and Garrett 1968) allows partial reabsorption of higher-frequency lee-wave energy when they are Doppler-shifted to lower frequency $(|k U| \downarrow$ $|f|)$ as they propagate upward or cross-stream into diminishing $|U|$. This is consistent with the bottom-intensified currents characterizing overprediction conditions (Waterman et al. 2014) and will be the focus of this paper treated in detail in section 3 .

Since lee waves have intrinsic (Lagrangian) frequencies that must satisfy $|f|<|k U|<N$, they will be confined inside their generating current $(|k U|>|f|)$ and unable to propagate long horizontal distances as suggested by Wright et al. (2014). Therefore, remote dissipation cannot explain the discrepancy. While much of the effort to explain the turbulence deficit has focused on the generation problem and bottom boundary condition (point iii), this paper will explore reabsorption through wave action $E / \omega_{L}$ conservation in the water column (point viii) where the deficit is reported (Waterman et al. 2014). While other explanations for the discrepancy between lee-wave power and turbulent dissipation cannot be ruled out, for example, points ii and iii, the finescale parameterization overestimating dissipation rates suggests that energized internal lee waves are finding an energy sink other than turbulence. The decreasing flow with height above bottom associated with this discrepancy (Waterman et al. 2014) favors loss to the mean flow through wave action conservation (point viii). Exchange with the mean flow has been considered in detail in the atmosphere for mountain 
lee waves propagating upward in vertical shear (Alexander 2003; Garner 2005), usually from the perspective of momentum conservation. Invariance of lee-wave action $E /|k U|$ is a more convenient constraint for dissipation considerations as part of an energy budget.

The "suppression of turbulence" in Antarctic Circumpolar Currents (Waterman et al. 2014) resembles recent numerical simulations of spontaneous generation of internal waves in a meandering Kuroshio Front (Nagai et al. 2015) in which the bulk of the generated waves are reabsorbed elsewhere by the balanced flow rather than being dissipated at small scales. These spontaneously generated waves were characterized by subinertial Eulerian frequencies $\left\{\omega_{E} \ll f_{\text {eff }}=[f(f+\zeta)]^{1 / 2}\right\}$ and superinertial Lagrangian frequencies $\left(\omega_{L}>f_{\text {eff }}\right)$ like internal lee waves. Nagai et al. argued that the waves redistribute rather than dissipate balanced energy. If the same holds true for lee waves, they would not represent the $0.2-0.75-\mathrm{TW}$ sink of balanced circulation energy, nor be as large a source of turbulent diapycnal mixing, as has been proposed (Scott et al. 2011; Nikurashin and Ferrari 2011; Wright et al. 2014; Melet et al. 2014; Trossman et al. 2015). Alternatively, if wave-wave interactions transfer trapped energy to free waves $\left(f<\omega_{E}<N\right)$ (Kunze et al. 1995) that dissipate elsewhere, that is, point vi above, lee waves would still represent a dominant sink for balanced flows.

Section 2 reviews pertinent lee-wave generation theory. It includes discussion of corrections for topographic blocking (saturation), that is, linearization of the bottom boundary condition, and shear instability, as $|k U| \downarrow \mid f$. Example topography spans the oceanographically relevant topographic wavenumber and spectral slope parameter range. Since this paper's focus is on water column process, not generation, lee-wave generation will be presented in terms of a linearized bottom boundary condition and 1D topography $h(x)$ for simplicity, but the impacts of $2 \mathrm{D}$ bathymetry $h(x, y)$ are pointed out. Readers familiar with lee-wave theory may wish to skip directly to the new material in section 3 that introduces conservation of wave action $E /|k U|$ (Bretherton and Garrett 1968) and quantifies its relevance for the suppressionof-turbulence problem in the same parameter space. For such readers, the lee-wave radiation cospectrum $\operatorname{coS}[w p](k)$ is given by (17) and displayed in Fig. 6 . Section 4 provides a summary and conclusions with discussion of assumptions and caveats.

\section{Lee-wave generation}

This section reviews lee-wave generation theory (e.g., Long 1955; Bell 1975; Baines 1995) in a rotating stratified fluid in order to construct a lee-wave energyflux cospectrum $\operatorname{coS}[w p](k)$. Internal lee waves are generated by flow $U$ over topography $h(x, y)$. Their phase speed is equal and opposite to the flow $\omega_{L} / k=-U$ such that their Eulerian frequency $\omega_{E}$ is zero and their intrinsic or Lagrangian frequency $\omega_{L}=-k U=|k U|$ where $k=2 \pi / \lambda_{x}$ and $\lambda_{x}$ is the along-stream topographic wavelength, for example, $h(x)=h_{0} \sin (k x)$. In the ocean, topographic variability is not confined to a single wavenumber but distributed over a range of lengthscales that can be described by a horizontal wavenumber spectrum for topographic height $S$ $[h](k)$. The flow/topography response radiates upward into the water column as lee waves for $|f / U|<$ $|k|<|N / U|$ but is evanescent (bottom-trapped) outside this topographic wavenumber band (Musgrave et al. 2016). Internal lee-wave properties are determined by flow speed $U$, buoyancy frequency $N$, Coriolis frequency $f$, the topographic height field $h(x, y)$ or its spectral distribution $S[h](k, \ell)$, and topographic wavevector $(k, \ell)$, where $\ell$ is the cross-stream wavenumber.

Although modeling efforts have focused on vertically and horizontally uniform flow (e.g., Nikurashin and Ferrari 2010a,b; Klymak 2018), horizontally and vertically confined bottom currents are typical of the ACC, where lee-wave generation theory and the finescale parameterization overpredict dissipation rates $\varepsilon$ (Waterman et al. 2014), as well as deep western boundary currents. ${ }^{1}$

Lee waves cannot propagate out of a spatially confined current. As $|k U| \downarrow f$ in the vertical, they encounter critical layers where their vertical wavenumber $|m| \rightarrow \infty$, group speed $|\mathbf{C g}| \rightarrow 0$ and amplitudes increase. As $|k U| \rightarrow f+N^{2} k^{2} /\left(2 f m^{2}\right)$ in the cross-stream direction, the cross-stream wavenumber $\ell$ passes through zero and lee waves will deflect inward from turning points.

Taking a high-latitude $|f|=1.3 \times 10^{-4} \mathrm{rad} \mathrm{s}^{-1}$ corresponding to $60^{\circ}$ latitude, abyssal $N=10^{-3} \mathrm{rad} \mathrm{s}^{-1}$ and $U=0.2 \mathrm{~m} \mathrm{~s}^{-1}$ (Fig. 14 of Waterman et al. 2014), the range of topographic wavelengths that can excite lee waves is $\sim 1-10 \mathrm{~km}$ (Fig. 1). These scales are not resolved by global bathymetric databases such as Smith and Sandwell (1997) but have been parameterized spectrally globally (Goff and Jordan 1988; Goff 2010; Goff and Arbic 2010). For much of the Southern Ocean, the horizontal wavenumber spectrum for

\footnotetext{
${ }^{1}$ Along-stream confluence and diffluence $U(x)$ will not be considered, though important for hydraulic flows over sills (Baines 1995).
} 


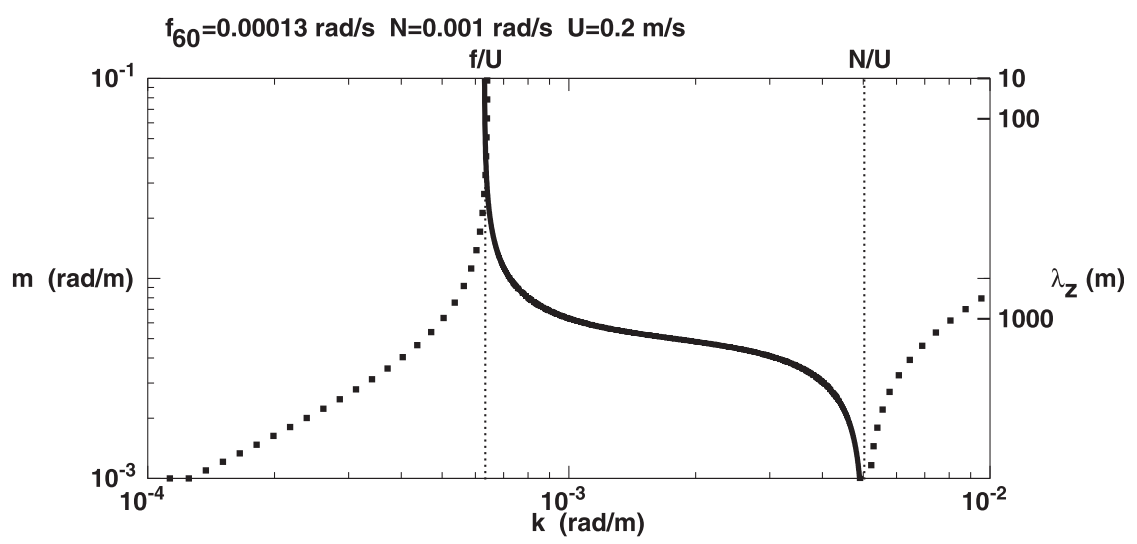

FIG. 1. Lee-wave vertical wavenumber $m\left(2 \pi / \lambda_{z}\right)$ as a function of topographic horizontal wavenumber $k$ from (2) for high-latitude Coriolis frequency $f=1.3 \times 10^{-4} \mathrm{rad} \mathrm{s}^{-1}$, abyssal $N=10^{-3} \mathrm{rad} \mathrm{s}^{-1}$, and bottom flow $U=0.2 \mathrm{~m} \mathrm{~s}^{-1}$. For topographic wavenumbers $k$ below $|f / U|$ $\left(\lambda_{h} \sim 10 \mathrm{~km}\right)$ and above $N / U\left(\lambda_{h} \sim 1 \mathrm{~km}\right)$, vertical wavenumbers $m$ are imaginary (dotted) corresponding to evanescent bottom-trapped motions with no bottom drag in the absence of bottom friction.

topographic height $S[h](k)$ transitions from roughly flat for wavelengths larger than $30-50 \mathrm{~km}$ to a red spectrum (Nikurashin and Ferrari 2010b; Brearley et al. 2013) in the band where internal lee waves are generated

$$
S[h](k, \ell)=\frac{2 \pi\left\langle h^{2}\right\rangle(\mu-2)}{k_{0} \ell_{0}} \frac{1}{\left(1+\frac{k^{2}}{k_{0}^{2}}+\frac{\ell^{2}}{\ell_{0}^{2}}\right)^{\mu / 2}}
$$

following Goff and Jordan (1988), where $\left\langle h^{2}\right\rangle$ is the topographic height variance, and $k_{0}$ and $\ell_{0}$ are peak wavenumbers for anisotropic topography. The lee-wave generation band $|f / U|<|k|<|N / U|$ has $k \gg k_{0}$, $\ell_{0}$. Nikurashin and Ferrari (2010b) state that $\mu \sim+3.5$ in Drake Passage. Corresponding 1D spectral slopes are $-2.5 \pm 0.3$.

With the horizontal wavevector $(k, \ell)$ set by the topography, and intrinsic frequency $|k U|$ by the along-stream topographic wavenumber $k$ and bottom flow speed $U$, the internal-wave dispersion relation controls the vertical wavenumber $m$ (Fig. 1) for flow over 1D topography $h(x)$

$$
m=k \sqrt{\frac{N^{2}-k^{2} U^{2}}{k^{2} U^{2}-f^{2}}}
$$

and for 2D topography $h(x, y)$

$$
m=\sqrt{k^{2}+\ell^{2}} \sqrt{\frac{N^{2}-k^{2} U^{2}}{k^{2} U^{2}-f^{2}}} .
$$

The vertical wavenumber $m$ is higher for $2 \mathrm{D}$ topography $h(x, y)$ at the same intrinsic frequency $|k U|$ because the horizontal wavenumber includes a cross-stream component $\ell$, reducing group velocities and energy-fluxes. For 1D topography, the inverse relation is

$$
k^{2}=\frac{\left(N^{2}-m^{2} U^{2}\right)}{2 U^{2}}\left[1+\sqrt{1+\frac{4 f^{2} m^{2} U^{2}}{\left(N^{2}-m^{2} U^{2}\right)^{2}}}\right] .
$$

Upward energy propagation from the bottom implies downward phase propagation as observed $(m<0)$ (Waterman et al. 2014). The vertical wavenumber $|m| \rightarrow \infty$ as $|k| \rightarrow|f / U|$ while $m \rightarrow 0$ (barotropic) as $|k| \rightarrow|N / U|$. The irrotational $\left(\omega_{L}=|k U| \gg|f|\right)$ and hydrostatic $\left(\omega_{L} \ll N\right)$ approximations will not be made here because $N$ becomes small, approaching $f$ in much of the abyssal ocean so that the internalwave frequency band is narrow. Thus, rotation, nonhydrostatics and topographic blocking cannot be ignored a priori.

For 1D topography $h(x)$, upstream group velocities

$$
\begin{aligned}
C g_{x} & =\frac{\partial \omega_{L}}{\partial k}=\frac{N^{2} m^{2} k}{\sqrt{N^{2} k^{2}+f^{2} m^{2}}\left(k^{2}+m^{2}\right)^{3 / 2}} \\
& =U\left(1-\frac{f^{2}}{k^{2} U^{2}}\right)\left(1-\frac{k^{2} U^{2}}{N^{2}}\right)
\end{aligned}
$$

are always less than the upstream phase speed

$$
C=\frac{\omega_{L}}{k}=\frac{\sqrt{N^{2} k^{2}+f^{2} m^{2}}}{k \sqrt{k^{2}+m^{2}}}=-U
$$

since the ratio 


$$
\frac{C g_{x}}{C}=\left(1-\frac{f^{2}}{k^{2} U^{2}}\right)\left(1-\frac{k^{2} U^{2}}{N^{2}}\right)
$$

is made up of two factors that are always less than one. Both factors are approximately one for continuum waves with $|f| \ll|k U| \ll N$ for which $k \ll m$ and $f m \ll N k$. Thus, continuum waves will radiate almost vertically above topographic obstacles while near-inertial and near-buoyancy lee-wave energy is swept downstream by the flow $U$ as it propagates upward.

Wave variables can be inferred from the linearized equations of motion and no-normal-flow bottom boundary condition

$$
\begin{aligned}
w & =\left(\mathbf{v}_{h} \cdot \nabla\right) h=(U+u) h_{x}+v h_{y} \sim U h_{x}=k U h \\
& \Rightarrow S[w](k)=U^{2} k^{2} S[h](k),
\end{aligned}
$$

where $u$ and $v$ are along- and across-stream leewave velocities. This sets lee-wave amplitudes at the boundary. Lee waves then propagate into the water column, carrying these properties. The linearized $1 \mathrm{D}$ expression to the right (and the spectral expression) hold for weak topography such that $u / U \approx m h=$ $k h\left[\left(N^{2}-k^{2} U^{2}\right) /\left(k^{2} U^{2}-f^{2}\right)\right]^{1 / 2} \ll 1$, that is, topography of small topographic slope compared to ray slope, $h_{x}<k / m\left\{=\left[\left(k^{2} U^{2}-f^{2}\right) /\left(N^{2}-k^{2} U^{2}\right)\right]^{1 / 2}\right.$ the internal-wave characteristic ray slope\}; this is similar to the topographic-blocking criterion $m h=$ $k h\left[\left(N^{2}-k^{2} U^{2}\right) /\left(k^{2} U^{2}-f^{2}\right)\right]^{1 / 2}<0.7$ (Garner 2005), that is, lee-wave vertical scales $m^{-1}$ must be longer than $70 \%$ of the topographic height $h$. Thus, the weak-topography approximation always breaks down as $|k U| \downarrow|f|$ (or equivalently $\mathrm{k} / \mathrm{m} \rightarrow 0$ ) so near-inertial lee waves will always be topographically blocked. These will prove to be associated with very weak energy-fluxes so are not important energetically. However, blocking and steering of flow by lower-wavenumber topography will modulate the flow $U$ felt by higher-wavenumber topography (Nikurashin et al. 2014; Klymak 2018) so will influence continuum lee-wave generation. This is not investigated here since the paper's primary focus is on water column not bottom generation processes. Generation will also be influenced by interactions among lee waves and the background internal wave field. For continuum waves $(f \ll|k U| \ll N)$, the weaktopography approximation can be expressed in terms of an inverse topographic Froude number $N h / U<0.7$ (0.4 in 2D; Nikurashin et al. 2014), which is usually used for broadband topographic spectra applications (Scott et al. 2011; Nikurashin and Ferrari 2010b; Nikurashin et al.2014) since the peak lee-wave radiation is centered in the linear continuum band. Scott et al. reported that the bulk of the ocean was characterized by the linear regime $(N h / U<0.7)$ such that corrections for saturation only reduce global lee-wave generation by $10 \%$. But topographic blocking has been shown to be importantly locally (e.g., Cusack et al. 2017). While the following assumes a linearized boundary condition, blocking at low wavenumbers $\sim(f / U)$ has nontrivial consequences for higher wavenumbers as discussed in section 4. Since our focus is on water column processes (section 3), not bottom generation, 1D topography $h(x)$ is assumed to avoid unnecessary complexity in the presentation.

For 1D topography $h(x)$, continuity implies that the along-stream lee-wave velocity $u$ is

$$
\begin{gathered}
u=-\frac{m w}{k}=-m U h=-\sqrt{\frac{N^{2}-k^{2} U^{2}}{k^{2} U^{2}-f^{2}}} k U h \\
\Rightarrow S[u](k)=U^{2}\left(\frac{N^{2}-k^{2} U^{2}}{k^{2} U^{2}-f^{2}}\right) k^{2} S[h](k),
\end{gathered}
$$

which simplifies to $u \sim-N h$ independent of $U$ for continuum waves $(|f| \ll|k U| \ll N)$.

Then, from $v$-momentum conservation, the crossstream wave velocity $v$ is

$$
\begin{aligned}
v & =-i \frac{f}{\omega_{L}} u=i f \sqrt{\frac{N^{2}-k^{2} U^{2}}{k^{2} U^{2}-f^{2}}} h \\
& \Rightarrow S[v](k)=f^{2}\left(\frac{N^{2}-k^{2} U^{2}}{k^{2} U^{2}-f^{2}}\right) S[h](k),
\end{aligned}
$$

from buoyancy $b$ conservation

$$
\begin{aligned}
b & =-\frac{i N^{2}}{k U} w=-i N^{2} h \\
& \Rightarrow S[b](k)=N^{4} S[h](k),
\end{aligned}
$$

and from nonhydrostatic $w$-momentum conservation, reduced pressure

$$
\begin{aligned}
p & =-\frac{\sqrt{N^{2}-k^{2} U^{2}} \sqrt{k^{2} U^{2}-f^{2}}}{k} h \\
& \Rightarrow S[p](k)=\frac{\left(N^{2}-k^{2} U^{2}\right)\left(k^{2} U^{2}-f^{2}\right)}{k^{2}} S[h](k) .
\end{aligned}
$$

For 2D topography, the lee-wave reduced pressure (11) is reduced by factor $k /\left(k^{2}+\ell^{2}\right)^{1 / 2}$.

Given a horizontal wavenumber spectrum for topography $S[h](k),(7)-(11)$ allow calculation of these and other lee-wave variables. Here, the following 


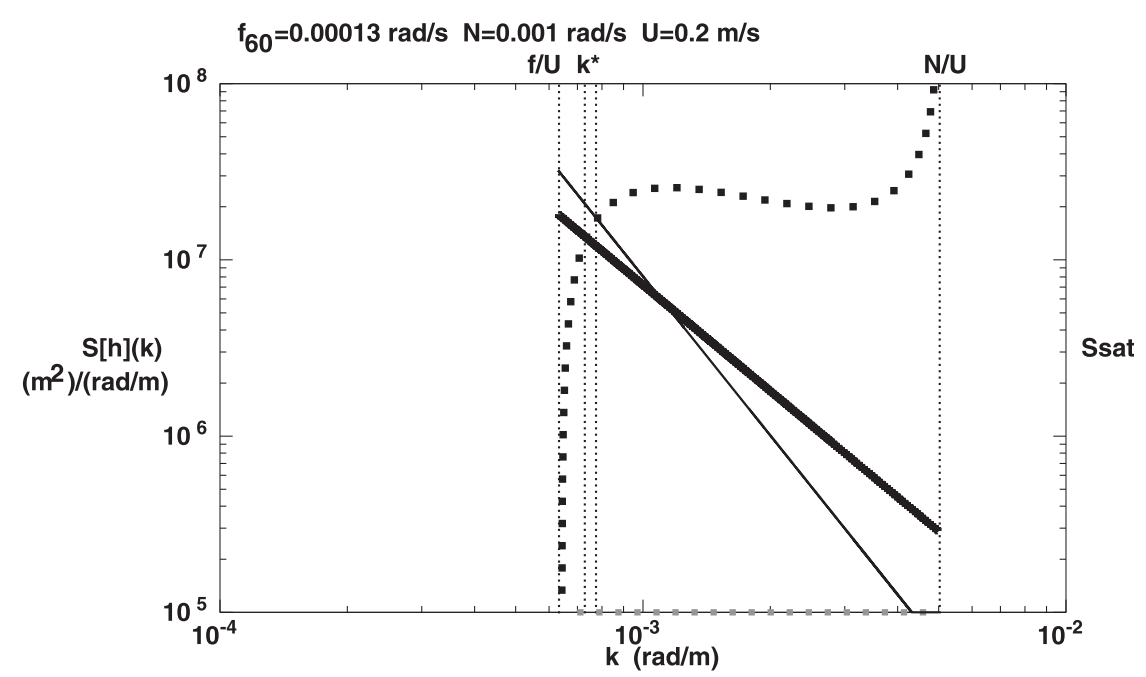

FIG. 2. Sample horizontal wavenumber $k$ spectra $S[h](k)$ (12) for topographic height $h$ going as $k^{-2}$ (thick solid) and $k^{-3}$ (thin solid), along with the topographic-blocking or saturation threshold (13) (dotted curve). When the topographic spectrum exceeds the topographic-blocking threshold as $k \downarrow f / U\left(k<k^{*}\right)$, the flow $U$ will only sense topography at the threshold level $0.7 U / N$. Thus, the minimum of either the topographic spectrum (solid) or the saturation spectrum (dotted) sets lee-wave radiation for any given $k$.

horizontal wavenumber $k$ spectra for topographic height $h$

$$
S[h](k)=\frac{(n-1)\left\langle h^{2}\right\rangle k^{n}}{U^{n-1}\left(f^{1-n}-N^{1-n}\right)}
$$

are used where $n<-1$ (solid curves, Fig. 2) to span the ocean range of topographic height spectral slopes. This form allows one to independently set the topographic height variance $\left\langle h^{2}\right\rangle=\int S[h](k) d k=10^{4} \mathrm{~m}^{2}$, flow speed $U$ and spectral slope $n$ in the lee-wave generation band $|f / U|<|k|<|N / U|$. To correct for topographic blocking as $|k U| \downarrow|f|$, the effective topographic spectrum generating lee waves

$$
S\left[h_{\mathrm{eff}}\right](k)=\frac{1}{2 m^{2} k}=\frac{\left(k^{2} U^{2}-f^{2}\right)}{2\left(N^{2}-k^{2} U^{2}\right) k^{3}}
$$

(dotted curve, Fig. 2) applies when the topographic spectrum is saturated at wavenumbers $k$, where $m^{-1}<$ $0.7 h$, equivalent to vertical strain $\xi_{z}=m \xi=m h>0.7$, where $\xi$ is the lee-wave vertical displacement. That is, the minimum of (12) or (13) is used at each wavenumber. This is equivalent to flow $U$ not experiencing topography $h$ more than $0.7 m^{-1}$ below the crests. For typical topographic heights and lengthscales, topographic blocking that leads to lee-wave saturation (13) only arises as $|k U| \downarrow|f|$ (Fig. 2).

The horizontal kinetic energy spectrum $S[\mathrm{HKE}](k)=$ $\{S[u](k)+S[v](k)\} / 2$, that is, (8) plus (9), is dominated by slow finescale near-inertial waves while available potential energy spectrum $S[\mathrm{APE}](k)=S[b](k) / N^{2} / 2$ from (10) is lower at low $k$ and higher at high $k$ (Fig. 3). Vertical wavenumber $m$ spectra are computed using dispersion relation (3) and

$$
\frac{d m}{d k}=\left(\frac{m}{k}\right)^{3}\left[\frac{2 k^{2} U^{2} f^{2}-k^{4} U^{4}-N^{2} f^{2}}{\left(N^{2}-k^{2} U^{2}\right)^{2}}\right],
$$

where $k$ is expressed in terms of $m$ in (3). Vertical wavenumber spectra exhibit peaks near $m=N / U$.

The gradient Froude number $\delta_{N}=\left|\mathbf{V}_{z}\right| / N=$ $\left(u_{z}^{2}+v_{z}^{2}\right)^{1 / 2} / N=m\left(u^{2}+v^{2}\right)^{1 / 2} / N$ spectrum

$$
S\left[\delta_{N}\right](k)=\left(\frac{N^{2}-k^{2} U^{2}}{k^{2} U^{2}-f^{2}}\right)^{2} \frac{\left(k^{2} U^{2}+f^{2}\right)}{N^{2}} k^{2} S[h](k)
$$

from (2), (8), and (9) reveals that shear instability $\left(\delta_{N}>2\right)$ occurs at higher $k$ and $|k U|$ than density overturning through vertical strain $\left|\xi_{z}\right|=|\partial \xi / \partial z|=m \xi=w /|k U|>1$

$$
S\left[\xi_{z}\right](k)=\left(\frac{N^{2}-k^{2} U^{2}}{k^{2} U^{2}-f^{2}}\right) k^{2} S[h](k),
$$

which is equivalent to topographic blocking $(m h>1)$ as $|k U| \downarrow|f|$ (Fig. 4), where $\xi=\int w d t=h$ is isopycnal displacement. Thus, near-inertial lee waves will break down into turbulence near the bottom immediately upon generation. For a $k^{-2}$ topographic spectrum (12), this amounts to about $10 \mathrm{~mW} \mathrm{~m}^{-2}$, or $2 \%$ of the total radiation dissipating locally, presumably over a wave lengthscale $m^{-1}$, unable to radiate away 


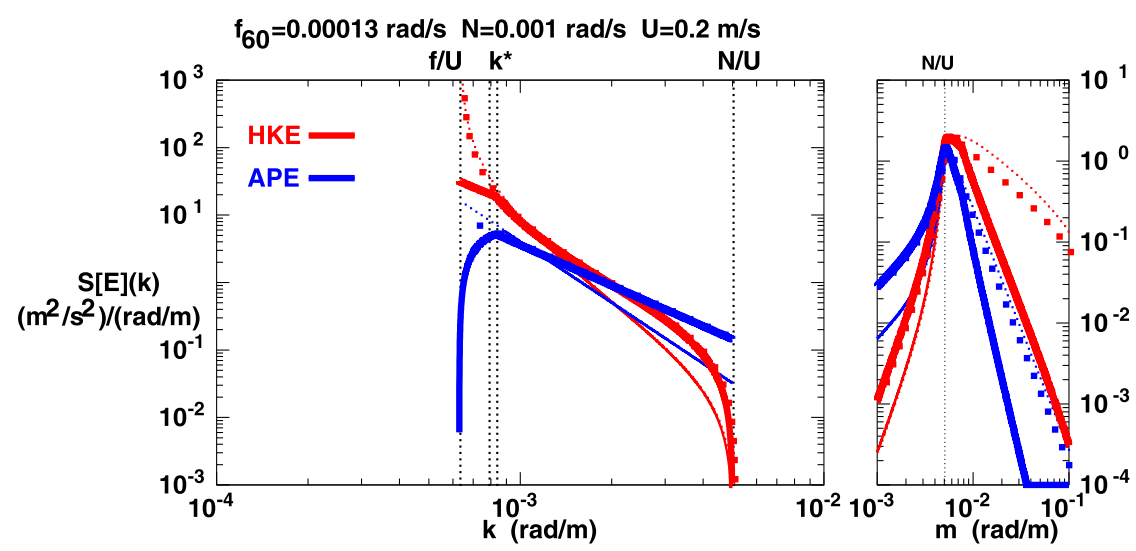

FIG. 3. (left) Horizontal wavenumber $k$ and (right) vertical wavenumber $m$ spectra for horizontal kinetic energy HKE $=\left(u^{2}+v^{2}\right) / 2$, that is, (8) $+(9)$ in text (red), and available potential energy APE $=b^{2} / N^{2} / 2$, that is, (10) (blue), for $k^{-2}$ (thick lines) and $k^{-3}$ (thin lines) topographic height spectra $S[h](k)$. At low $k\left(k<k^{*}\right)$ and high $m(>N / U)$, saturated (topographically blocked) spectra are the lower (solid) curves while the full linear responses are the higher (dotted) curves. The peak in the vertical wavenumber $m$ spectrum corresponds to the continuum band where $m$ is approximately constant (Fig. 1). High-latitude Coriolis frequency $f$, abyssal buoyancy frequency $N$, and mean flow $U$ are as indicated in the header.

(Fig. 5). Note that the gradient Froude number $\delta_{N}=m u / N=m^{2} U h / N$ [from $1 \mathrm{D}$ continuity (8)] is not identical to the topographic Froude number $\delta_{t}=U /(N h)$ except where $m h=1$ as $|k U| \downarrow|f|$ because of saturation. At higher $k, \delta_{N} / \delta_{t}=m^{2} h^{2}<1$.

Of most relevance here is the vertical energy-flux, or lee-wave radiation, $\langle w p\rangle$ cospectrum
$\operatorname{coS}[w p](k)=U \sqrt{N^{2}-k^{2} U^{2}} \sqrt{k^{2} U^{2}-f^{2}} S[h](k)$,

which vanishes as $|k U| \rightarrow|f|$ and $|k U| \rightarrow N$, and peaks at intermediate wavenumbers $|f / U|<|k|<|N / U|$ in the continuum band (Fig. 6). Divergence of the energy-flux is known as pressure-work and is a forcing term in energy conservation. From the variance-preserving

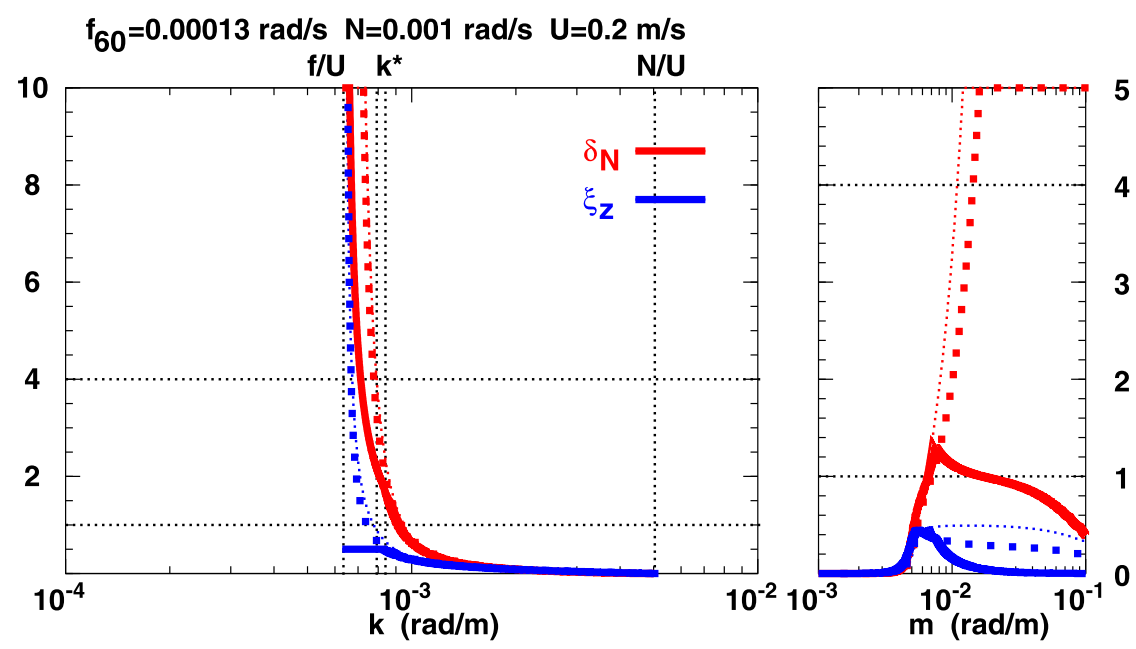

FIG. 4. Variance-preserving (left) horizontal wavenumber $k$ and (right) vertical wavenumber $m$ spectra for gradient Froude number $\delta_{N}=\left|\mathbf{V}_{z}\right| / N$ (red) and vertical strain $\xi_{z}=$ $\partial \xi / \partial z=m h$ (blue) for $k^{-2}$ (thick lines) and $k^{-3}$ (thin lines) topographic height spectra $S[h](k)$. At low $k$ and high $m$, saturated (topographically blocked) spectra are the lower (solid) curves in contrast to the full linear topographic response (dotted curves). Note that $\delta_{N}^{2}$ exceeds a critical value of 4 as $|k| \downarrow|f| U \mid$ at similar $k$ to topographic saturation, $k^{*}(14)$. High-latitude Coriolis frequency $f$, abyssal buoyancy frequency $N$, and mean flow $U$ are as indicated in the header. 

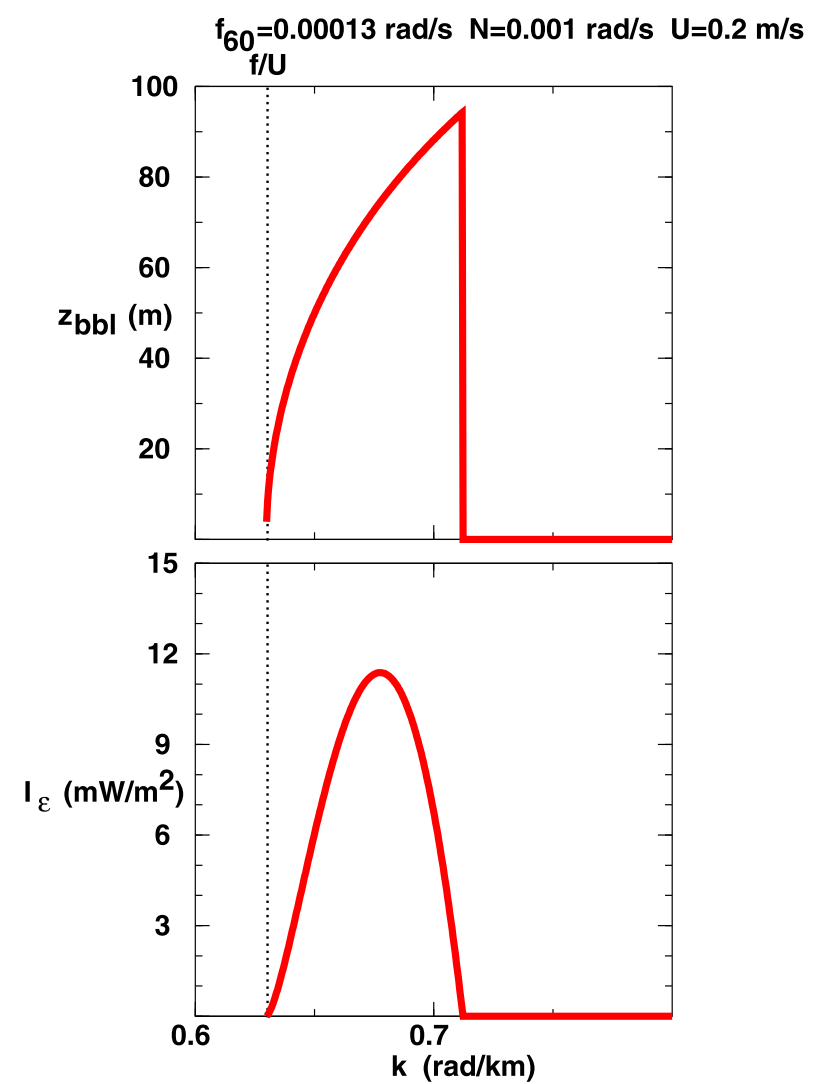

FIG. 5. (top) Turbulent bottom-boundary-layer thickness $z_{\mathrm{bbl}}=m^{-1}$ and (bottom) vertically integrated dissipation rate $\int_{\varepsilon}=w p\left(\delta_{N}^{2}-4\right) / \delta_{N}^{2}$ associated with shear-unstable near-inertial lee waves with gradient Froude number $\delta_{N}>2$ as $k \downarrow f / U$ for a $k^{-2}$ topographic height spectrum modified for saturation as $k \downarrow f / U$ (Fig. 4). Maximum dissipation rates $\varepsilon=m \int_{\varepsilon} \sim 10^{-8} \mathrm{~W} \mathrm{~kg}^{-1}$ in this band.

form of (17) with (12), the peak energy-flux is $f N U\left\langle h^{2}\right\rangle$ at $|k U|=(f N)^{1 / 2}$ for a $k^{-2}$ topographic height spectrum. For 2D topography, lee-wave radiation (17) is reduced by factor $k /\left(k^{2}+\ell^{2}\right)^{1 / 2}$. The vertical energy-flux can be related to the bottom form-drag $p h_{x}$, vertical momentum-flux $u w$ and vertical component of the Eliassen-Palm flux $u w-f v b / N^{2}$

$$
\langle w p\rangle=U\left\langle p h_{x}\right\rangle=-U\left(\langle u w\rangle-\frac{f}{N^{2}}\langle v b\rangle\right)
$$

(Fig. 7). Losses from radiating lee waves will be partitioned between either (i) exchange with the mean flow through Eliassen-Palm flux (Eliassen and Palm 1961) forcing or (ii) dissipation $\int \varepsilon d z$. Divergence of the Eliassen-Palm flux is a forcing term in momentum conservation for a vertically sheared balanced flow.

\section{Lee-wave action $E /|k U|$ conservation}

While recent oceanographic papers have assumed that the only sink for lee-wave radiation is turbulent dissipation so focused on lee-wave generation (Scott et al. 2011; Nikurashin and Ferrari 2011; Sheen et al. 2013; Waterman et al. 2013; Wright et al. 2014; Melet et al. 2014; Trossman et al. 2015, 2016), conservation of wave action $E /|k U|$ (Bretherton and Garrett 1968) dictates that some fraction can be transferred back to the mean flow as $|k U| \downarrow|f|$ since

$$
\frac{\tilde{D}}{D t}\left(\frac{E}{\omega_{L}}\right)=0 \Rightarrow \frac{E}{E_{0}}=\frac{k U}{k U_{0}}=\frac{U}{U_{0}},
$$

where $\tilde{D} / D t$ is the time derivative following a wave packet of energy $E$ and intrinsic or Lagrangian frequency $\omega_{L}=|k U|$, and the 0 subscript denotes, for example, values at the point of generation. In other words, the energy of a wave packet propagating in a shear flow $U(x, y, z)$ is not conserved because of exchange with the background mean. For lee waves generated in a spatially confined current, as $|k U|$ decreases, wave energy $E$ decreases as it is transferred to the mean; likewise, if $|k U|$ increases away from the generation site, wave energy $E$ will grow at the expense of the mean. For decreasing $|k U|$, nearinertial lee waves are already close to the lower bound of their intrinsic frequency $|k U|$ so will exchange little energy with a diminishing background mean, making most of their energy available for loss to turbulent dissipation (Fig. 6). This is consistent with the finding that the bulk of near-inertial wave energy trapped in a Gulf Stream warm-core ring is lost to dissipation (Kunze et al. 1995) because vortextrapped waves are already near-inertial $\left\{[f(f+\zeta)]^{1 / 2}<\right.$ $\left.\omega_{L}<f\right\}$. On the other hand, lee waves in the continuum band $|k U| \gg|f|$, which dominates generation (Fig. 6), will lose a large portion of their energy to the mean as they are Doppler-shifted toward $f$, with only a small fraction available for turbulence (Fig. 6). In the absence of rotation $(f=0)$, all energy can be reabsorbed by the mean for infinitesimal wave amplitude as $|k U| \rightarrow 0$ and $E \rightarrow 0$. In a rotating fluid, $|k U|>|f|$ limits the fraction that can be absorbed to be at most

$$
\frac{E_{0}-E_{f}}{E_{0}} \leq \frac{k U_{0}-f}{k U_{0}}
$$

since $f$ is the lowest frequency that an internal lee wave can be Doppler-shifted to, where $U_{0}$ is the bottom flow speed. This will be referred to as the exchange or 


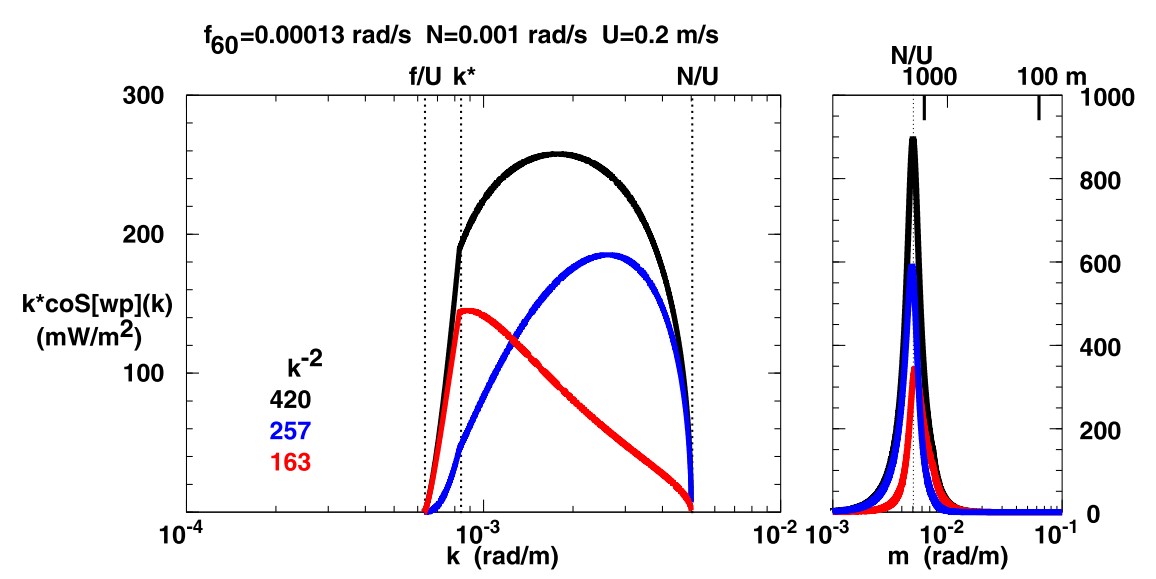

FIG. 6. (left) Variance-preserving horizontal wavenumber $k$ cospectra for lee-wave energy flux $\langle w p\rangle$ (17) from a $k^{-2}$ topographic height spectrum $\mathrm{S}[h](k)$ (12). Topographic blocking (saturation) is taken into account as $|k U| \downarrow|f|\left(k<k^{*}\right)$. Wave action $\mathrm{E} /|k U|$ conservation (19) has been used to partition the $w p$ cospectra into fractions that will be reabsorbed into the mean (20) (blue) vs dissipated (21) (red) assuming infinitesimal amplitude so that $|k U| \downarrow|f|$ before wave breaking; if waves break before reaching the $|k U|=|f|$ critical layer, more energy will be dissipated and less reabsorbed. Numbers inside the left panel correspond to covariances under the spectra. (right) Variance-preserving vertical wavenumber $m$ cospectra reveal that lee-wave radiation peaks at vertical wavenumbers $m \sim N / U$. Dissipation (red) is skewed to slightly higher $m$ and absorption (blue) to slightly lower $m$.

absorptive fraction. This implies that the dissipative fraction is at least

$$
\frac{E_{f}}{E_{0}}=\frac{\int_{\varepsilon}}{\left\langle w^{\prime} p^{\prime}\right\rangle} \geq \frac{f}{k U_{0}},
$$

where $\int_{\varepsilon}=\int \varepsilon d V$ (Fig. 6). The maximum exchange fraction (20) is $(N-f) / N$ and minimum dissipative fraction (21) $f / N$ for lee waves generated at $|k U|$ near $N$. This suggests that the dissipative fraction will be smaller at higher stratifications and lower latitudes, that is, for a broader internal-wave frequency bandwidth.

For finite-amplitude lee waves, the absorptive fraction will depend on the frequency $k U_{1}$ at which waves break as $\left(k U_{0}-k U_{1}\right) / k U_{0}=\left(U_{0}-U_{1}\right) / U_{0}$, leaving fraction $k U_{1} / k U_{0}=U_{1} / U_{0} \geq f / k U_{0}$ available for nonlinear transfer to free wave radiation, turbulent dissipation and mixing. Thus, breaking before encountering a critical layer will produce a larger dissipative fraction.

A lee wave's dissipative fraction (21) is a function of the generating frequency $|k U|$. The net dissipative fraction from all wavenumbers $k$ depends on the distribution of topographic height $h$ with wavenumber $k$, that is, the topographic height spectrum $S[h](k) \sim k^{n}(12)$, and the bandwidth $N / f$. Provided that the spectral slope $n$ is constant, the net dissipative fraction $\int\{f S[w p](k) / k U\}$ $d k / \int S[w p](k) d k$ does not depend on $U$ because it can be expressed as $f \int\left[g\left(\omega_{L}\right) / \omega_{L}\right] d \omega_{L} / \int g\left(\omega_{L}\right) d \omega_{L}$ with both integrals ranging from $f$ to $N$ \{where $g\left(\omega_{L}\right)=\left[\left(N^{2}-\right.\right.$ $\left.\left.\left.\omega_{L}^{2}\right)\left(\omega_{L}^{2}-f^{2}\right)\right]^{1 / 2} \omega_{L}^{n}\right\}$. A higher net dissipative fraction is available for (i) lower $N / f$ as found in the abyss and higher latitudes and (ii) redder topographic spectra (more negative topographic spectral slopes $n$ ) such that a greater fraction of the lee-wave generation occurs at near-inertial $|k U|$ (Fig. 8). For low-latitude pycnocline stratification $(N / f \sim 100)$, the net dissipative fraction ranges from 0.2 to 0.5 . But it increases for high latitudes and low abyssal stratification. For Coriolis frequency $|f|=1.3 \times 10^{-4} \mathrm{rad} \mathrm{s}^{-1}$, corresponding to the $60^{\circ}$ latitude of the Antarctic Circumpolar Currents, $N=10^{-3} \mathrm{rad} \mathrm{s}^{-1}(N / f \sim 7)$, flow speed $U=0.2 \mathrm{~m} \mathrm{~s}^{-1}$, rms topographic height $h_{\mathrm{rms}}=100 \mathrm{~m}$, and topographic height spectral slopes $n=-2.5 \pm 0.3$ characterizing the Southern Ocean (Nikurashin and Ferrari 2010b; Waterman et al. 2014), lee waves radiate at rate $\sim 420 \mathrm{~mW} \mathrm{~m}^{-2}$ when adjusted for saturation as $|k U| \downarrow|f|$, peaking in the continuum band $\left(k=2 \times 10^{-3} \mathrm{rad} \mathrm{m}^{-1}, m=5 \times 10^{-3} \mathrm{rad} \mathrm{m}^{-1}\right)$ (Fig. 6). Roughly $2 \%$ is lost to bottom-boundary-layer turbulence in the near-inertial band (Fig. 5) where lee waves are shear unstable upon generation (Fig. 4). Of the remainder, roughly half will be lost to the mean as $|k U| \downarrow|f|$, leaving $0.44-0.56$ available for the net turbulent dissipative fraction (Fig. 6). Thus, while lee waves are most effective as a dissipative sink for balanced flow in the high-latitude abyss such as the 


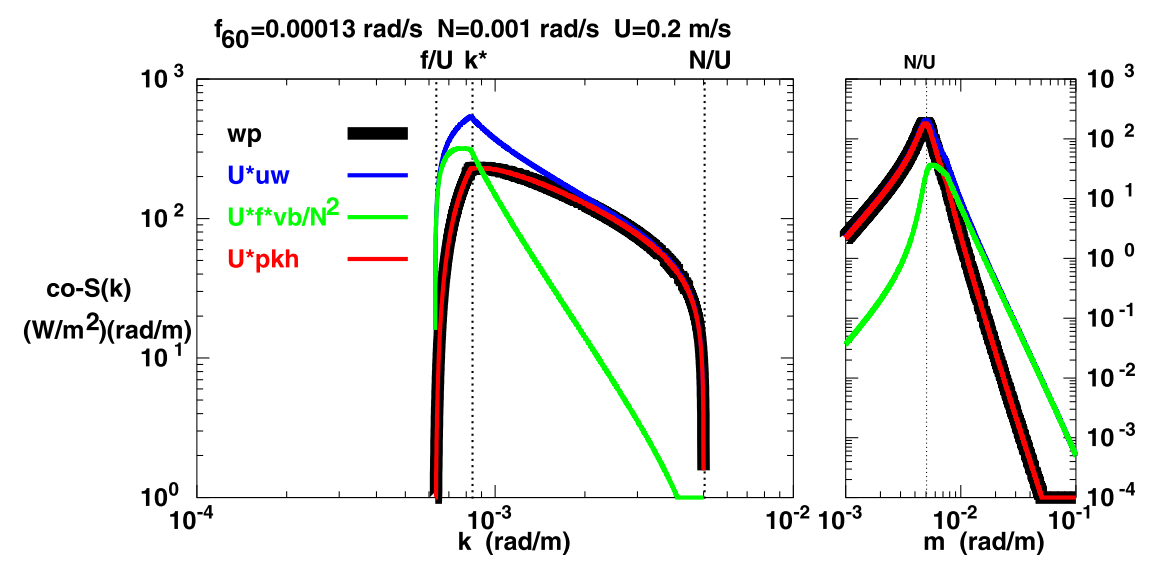

FIG. 7. (left) Horizontal wavenumber $k$ and (right) vertical wavenumber $m$ spectra for vertical energy-flux $w p$ (black), scaled vertical momentum-flux $U u w$ (blue), and cross-stream buoyancy-flux $U f v b / N^{2}$ (green) components of the vertical Eliassen-Palm (EP) flux, and scaled bottom drag $U p h_{x}=k U p h$ (red) for a $k^{-2}(12)$ topographic spectra $S[h](k)$. Variables have been scaled to have the same units as energy-flux to illustrate the equivalence of the different terms as in (18). Topographic blocking (saturation) is taken into account as $|k U| \downarrow|f|$ $\left(k<k^{*}\right)$. High-latitude Coriolis frequency $f$, abyssal buoyancy frequency $N$, and mean flow $U$ are indicated in the header.

Antarctic Circumpolar Currents in the Southern Ocean, even there they are only $\sim 0.5$ effective. This assumes (i) a linearized bottom boundary condition (7) with (ii) the minimum of the topographic spectrum (12) or saturated topographic spectrum (13), which is discussed further in section 4, (iii) $|U|$ decreases with height above bottom consistent with the conditions for suppression of turbulence reported by Waterman et al. (2014), and (iv) waves do not break until $|k U| \sim f$.

\section{Conclusions}

This paper explored one of several possible explanations for the suppression of turbulence observed in

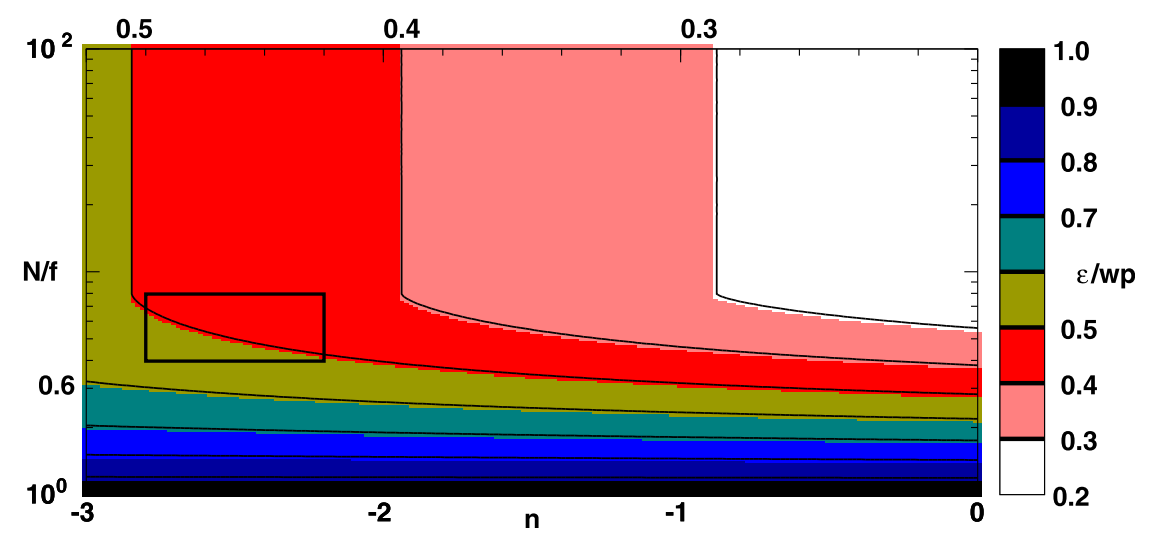

FIG. 8. Dependence of the dissipative fraction of lee-wave generation $\int_{\varepsilon} / w p(21)$ on $N / f$ and topographic spectral slope $n$ under the small-amplitude approximation, where $S[h](k) \sim k^{n}$. For $N \downarrow f$ as in the high-latitude and abyssal ocean, the topographic bandwidth $f / U<k<N / U$ becomes narrow and the dissipative fraction becomes $\sim 1$, independent of topographic spectral slope. Numbers $0.3-0.6$ along the upper and left axes are $\int_{\varepsilon} / w p$ contour labels, replicating the color bar on the right. For the mid and lowlatitude pycnocline $(N / f \sim 10-100)$, the dissipative fraction decreases from about $\sim 0.56$ for topographic spectral slopes $n=-3$ to $\sim 0.35$ for topographic spectral slopes $n=0$. The black box encloses the parameter space characterizing the Antarctic Circumpolar Currents $[n=-2.5 \pm 0.3$ (Nikurashin and Ferrari 2010b); N/f $\sim 5-10$ (Waterman et al. 2014)], where the dissipative fraction is $0.44-0.56$. 
Southern Ocean where microstructure measurements find dissipation rates that are smaller than predicted by lee-wave generation theory and finescale parameterizations (Sheen et al. 2013; Waterman et al. 2013, 2014; Cusack et al. 2017; Takahashi and Hibiya 2019). Transfer of lee-wave energy back to the balanced flow through wave action $E /|k U|$ conservation (Bretherton and Garrett 1968) can account for a factor of 2 reduction in turbulence production with the remaining portion of lee-wave power reabsorbed by the balanced flow for conditions typical of the Southern Ocean (Waterman et al. 2014). The low $N / f$ of the Southern Ocean abyss favors a lower absorptive fraction (Fig. 8) than lower latitudes and higher stratification. Nevertheless, it cannot fully explain the observed factor of 3-5 suppression (Waterman et al. 2014) so cannot fully account for the reported discrepancy between turbulent dissipation and lee-wave generation. Lee waves also become less effective dissipative sinks for bluer topographic height spectra. This reduction of lee-wave dissipation by wave action conservation to 0.1-0.37 TW makes them comparable to bottom drag (Arbic and Flierl 2004; Sen et al. 2008; Arbic et al. 2009) rather than the dominant sink.

Reabsorption of lee-wave energy back into the balanced flow is a mechanism for redistributing rather than dissipating balanced energy by homogenizing the generating/trapping current. Internal-wave redistribution of balanced flows is a well-established phenomenon in the atmosphere, in particular for (i) mountain lee waves (Alexander 2003; Garner 2005), (ii) driving the quasi-biennial oscillation (Lindzen and Holton 1968), (iii) driving the Madden-Julian oscillation (Biello and Majda 2005), (iv) influencing middle atmosphere winds (Holton and Alexander 2000), and (v) acting as a drag on lower stratospheric and tropospheric winds (McFarlane 1987; Scinocca and McFarlane 2000).

The results found here come with substantial caveats. The model neglects interactions among lee waves as well as with the background internal-wave field, tides, bottom-trapped topographic waves (Rhines 1970), the subinertial $(|k U|<|f|)$ and superbuoyancy $(|k U|>N)$ forced evanescent response (Musgrave et al. 2016; Klymak 2018) including blocking and splitting (Nikurashin et al. 2014), bottom Ekman shear and shed vortices (D'Asaro 1988). A particular concern is the linearized boundary condition (7) which assumes that blocking at lower topographic wavenumbers does not impact lee-wave generation at higher wavenumbers (Fig. 2) following Baines (1995), Nikurashin and Ferrari (2010a,b), Scott et al. (2011), Nikurashin and Ferrari (2011), Wright et al. (2014), and Nikurashin et al. (2014). Since topographic heights at lower wavenumbers are larger than those at higher wavenumbers, this is implausible. Higher topographic wavenumbers cannot be treated in isolation of the influences by lower topographic wavenumbers (that block and split near-bottom flows). For 1D topography $h(x)$, the smaller-scale bottom topography downstream will be shielded from the flow by blocking, quenching lee-wave generation. For 2D topography $h(x, y)$, flow can be steered around topography (for seamounts and saddle points) or blocked (for ridges and depressions) so that smaller-scale topography will feel flow modulated by the larger-scale topography (Klymak 2018). Nikurashin et al. (2014) found reduced lee-wave generation for superinertial 2D topography while wavenumber spectra of temperature from Klymak's (2018) model show higher levels for full topography than high-passed topography in the internal-lee-wave band at $300 \mathrm{mab}$, and comparable at 1000 mab (his Fig. 5), indicating that blocking and splitting can diminish or enhance lee-wave generation. Klymak (2018) suggested that amplification of near-bottom flow $U$ by larger-scale topography in his simulations shifted the lee-wave generation band to lower wavenumbers which have higher topographic height variance. Thus, lee-wave generation for $k>f / U$ will be modified from the linear generation model presented in section 2. Lee-wave generation will depend on details of topographic geometry that are not available from the spectral representations (Goff and Jordan 1988; Goff 2010; Goff and Arbic 2010), for example, elevations versus depressions.

Nevertheless, the central point here, that wave action conservation will reduce the fraction of lee-wave generation lost to turbulent dissipation and mixing, still needs to be taken into account in energy budgets for the balanced flow. Moreover, since the net dissipative fraction is independent of $U$ for uniform topographic spectral slope, it will be independent of modulations of the near-bottom flow $U$ by topography at $k<\sim O(f / U)$ where blocking and splitting are expected (Fig. 2).

Even if the dissipative fraction is robust, it is unclear that it is responsible for the deficit reported by Waterman et al. (2014). Wave action conservation and other mechanisms for the turbulence deficit are being investigated with ongoing numerical simulations. Other plausible explanations include (i) overestimation of leewave generation because of blocking and splitting of near-bottom flows by lower-wavenumber 2D topography $h(x, y)$ (Nikurashin et al. 2014; Trossman et al. 2015, 2016), although Klymak (2018) reported that blocking and hydraulic effects from larger-scale topography $(k<f / U)$ dominated near-bottom dissipation by factors of 2-3; (ii) microstructure sampling biases in a highly heterogeneous turbulence field (Waterman et al. 2014; 
Klymak 2018); (iii) internal wave-wave interactions transferring energy into waves free to propagate out of the jets $\left(f<\omega_{E}<N\right)$; and (iv) advection downstream and propagation cross stream (Zheng and Nikurashin 2019). These mechanisms may work in concert to reduce turbulence in the local water column but not all of them reduce lee waves as sinks for balanced flow as does wave action conservation. The puzzle of how the balanced mean and eddy fields dissipate their $1 \mathrm{TW}$ of generation remains (Ferrari and Wunsch 2009; Scott et al. 2011; Nikurashin and Ferrari 2011; Wright et al. 2014; Melet et al. 2014).

Acknowledgments. David Trossman and Jody Klymak provided invaluable guidance. Amala Mahadevan, Amit Tandon, and an anonymous reviewer provided helpful comments for clarifying the manuscript. This work was supported by NSF Grants OCE-1756093, OCE-1829082, and OCE-1829190.

\section{REFERENCES}

Alexander, M. J., 2003: Gravity wave fluxes. Encyclopedia of Atmospheric Sciences, Academic Press, 1699-1705, https:// doi.org/10.1016/B0-12-227090-8/00309-2.

Arbic, B. K., and G. Flierl, 2004: Baroclinically unstable geostrophic turbulence in the limit of strong and weak bottom Ekman friction: Application to mid-ocean eddies. J. Phys. Oceanogr., 34, 2257-2273, https://doi.org/10.1175/15200485(2004)034<2257:BUGTIT>2.0.CO;2.

bottom-boundary-layer dissipation of the oceanic general circulation from global high-resolution models. J. Geophys. Res., 114, C02024, https://doi.org/10.1029/2008JC005072.

Baines, P. G., 1995: Topographic Effects in Stratified Flows. Cambridge University Press, 482 pp.

Bell, T. H., 1975: Topographically-generated internal waves in the open ocean. J. Geophys. Res., 80, 320-327, https://doi.org/ 10.1029/JC080i003p00320.

Biello, J., and A. Majda, 2005: A new multiscale model for the Madden-Julian oscillation. J. Atmos. Sci., 62, 1694-1721, https://doi.org/10.1175/JAS3455.1.

Brearley, J. A., K. L. Sheen, A. C. Naveira Garabato, D. A. Smeed, and S. Waterman, 2013: Eddy-induced modulation of turbulent dissipation over rough topography in the Southern Ocean. J. Phys. Oceanogr., 43, 2288-2308, https://doi.org/10.1175/ JPO-D-12-0222.1.

Bretherton, F. P., and C. J. R. Garrett, 1968: Wavetrains in inhomogeneous moving media. Proc. Roy. Soc. London, 302A, 529-554, https://doi.org/10.1098/rspa.1968.0034.

Cusack, J. M., A. C. Naveira Garabato, D. A. Smeed, and J. B. Girton, 2017: Observation of a large lee wave in the Drake Passage. J. Phys. Oceanogr., 47, 793-810, https://doi.org/ 10.1175/JPO-D-16-0153.1.

D'Asaro, E. A., 1988: Generation of submesoscale vortices: A new mechanism. J. Geophys. Res., 93, 6685-6693, https://doi.org/ 10.1029/JC093iC06p06685.

_ C. M. Lee, L. Rainville, R. Harcourt, and L. Thomas, 2011: Enhanced turbulence and energy dissipation at ocean fronts. Science, 332, 318-322, https://doi.org/10.1126/science.1201515.
Eliassen, A., and E. Palm, 1961: On the transfer of energy in stationary mountain waves. Geofys. Publ. Oslo, 22, 1-23.

Ferrari, R., and C. Wunsch, 2009: Ocean circulation kinetic energy: Reservoirs, sources and sinks. Annu. Rev. Fluid Mech., 41, 253282, https://doi.org/10.1146/annurev.fluid.40.111406.102139.

Garner, S. T., 2005: A topographic-drag closure built on an analytical base flux. J. Atmos. Sci., 62, 2302-2315, https://doi.org/ 10.1175/JAS3496.1.

Gille, S. T., 1997: The Southern Ocean momentum balance: Evidence for topographic effects from numerical model output and altimeter data.J. Phys. Oceanogr., 27, 2219-2232, https://doi.org/ 10.1175/1520-0485(1997)027<2219:TSOMBE >2.0.CO;2.

Goff, J. A., 2010: Global prediction of abyssal hill root-meansquare heights from small-scale altimetric gravity variability. J. Geophys. Res., 115, B12104, https://doi.org/10.1029/ 2010JB007867.

— morphology: Inversion of Sea beam data for second-order statistics. J. Geophys. Res., 93, 13 589-13 608, https://doi.org/ 10.1029/JB093iB11p13589.

, and B. K. Arbic, 2010: Global prediction of abyssal hill roughness statistics for use in ocean models from digital maps of paleo-spreading rate, paleo-ridge orientation and sediment thickness. Ocean Modell., 32, 36-43, https://doi.org/10.1016/ j.ocemod.2009.10.001.

Gregg, M. C., and E. Kunze, 1991: Shear and strain in Santa Monica Basin. J. Geophys. Res., 96, 16 709-16 719, https://doi.org/ 10.1029/91JC01385.

— T. T. Banford, and D. P. Winkel, 2003: Reduced mixing from the breaking of internal waves in equatorial ocean waters. Nature, 422, 513-515, https://doi.org/10.1038/nature01507.

Holton, J. R., and M. J. Alexander, 2000: The role of waves in the transport circulation of the middle atmosphere. Atmospheric Science Across the Stratopause, Geophys. Monogr., Vol. 123, Amer. Geophys. Union, 21-35.

Ijichi, T., and T. Hibiya, 2017: Eikonal calculations for energy transfer in the deep-ocean internal wave field near mixing hotspots. J. Phys. Oceanogr., 47, 199-210, https://doi.org/ 10.1175/JPO-D-16-0093.1.

Klymak, J. M., 2018: Nonpropagating form drag and turbulence due to stratified flow over large-scale abyssal-hill topography. J. Phys. Oceanogr., 48, 2383-2395, https://doi.org/10.1175/ JPO-D-17-0225.1.

Kunze, E., 2017: Internal-wave-driven mixing: Global geography and budgets. J. Phys. Oceanogr., 47, 1325-1345, https:// doi.org/10.1175/JPO-D-16-0141.1.

— topography in turbulent mixing of the global ocean. Oceanography, 17, 55-60, https://doi.org/10.5670/oceanog.2004.67.

- R.W. Schmitt and J.M. Toole, 1995: The energy balance in a warm-core ring's near-inertial critical layer. J. Phys. Oceanogr., 25, 942-957, https://doi.org/10.1175/1520-0485(1995) 025<0942:TEBIAW >2.0.CO;2.

— E. Firing, J. M. Hummon, T. K. Chereskin, and A. M. Thurnherr, 2006: Global abyssal mixing inferred from lowered ADCP shear and CTD strain profiles. J. Phys. Oceanogr., 36, 1553-1576, https://doi.org/10.1175/JPO2926.1.

Lindzen, R., and J. R. Holton, 1968: A theory of the quasi-biennial oscillation. J. Atmos. Sci., 25, 1095-1107, https://doi.org/ 10.1175/1520-0469(1968)025<1095:ATOTQB > 2.0.CO;2.

Long, R. R., 1955: Some aspects of the flow of stratified fluids. Part 3: Continuous density gradient. Tellus, 7, 341-357, https:// doi.org/10.3402/tellusa.v7i3.8900. 
McFarlane, N. A., 1987: The effect of orographically-excited gravity wave drag on the general circulation of the lower stratosphere and troposphere. J. Atmos. Sci., 44, 1775-1800, https://doi.org/ 10.1175/1520-0469(1987)044<1775:TEOOEG >2.0.CO;2.

Melet, A., R. Hallberg, S. Legg, and M. Nikurashin, 2014: Sensitivity of the ocean state to lee-wave-driven mixing. J. Phys. Oceanogr., 44, 900-921, https://doi.org/10.1175/JPO-D-13-072.1.

Molemaker, M. J., J. C. McWilliams, and X. Capet, 2010: Balanced and unbalanced routes to dissipation in an equilibrated Eady flow. J. Fluid Mech., 654, 35-63, https://doi.org/10.1017/ S0022112009993272.

Musgrave, R. C., R. Pinkel, J. A. MacKinnon, and J. R. Mazloff, 2016: Stratified tidal flow over a tall ridge above and below the turning latitude. J. Fluid Mech., 793, 933-957, https://doi.org/ 10.1017/jfm.2016.150.

Nagai, T., A. Tandon, E. Kunze, and A. Mahadevan, 2015: Spontaneous generation of internal waves by the Kuroshio Front. J. Phys. Oceanogr., 45, 2381-2406, https://doi.org/10.1175/ JPO-D-14-0086.1.

Naveira Garabato, A. C., K. L. Polzin, B. A. King, K. J. Heywood, and M. Visbeck, 2004a: Widespread intense turbulent mixing in the Southern Ocean. Science, 303, 210-213, https://doi.org/ 10.1126/science.1090929.

— K. K. I. C. Oliver, A. J. Watson, and M. J. Messias, 2004b: Turbulent diapycnal mixing in the Nordic Seas. J. Geophys. Res., 109, https://doi.org/10.1029/2004JC002411.

Nikurashin, M., and R. Ferrari, 2010a: Radiation and dissipation of internal waves generated by geostrophic motions impinging on small-scale topography: Theory. J. Phys. Oceanogr., 40, 1055-1074, https://doi.org/10.1175/2009JPO4199.1.

—_, and — 2010b: Radiation and dissipation of internal waves generated by geostrophic motions impinging on small-scale topography: Application to the Southern Ocean. J. Phys. Oceanogr., 40, 2025-2042, https://doi.org/10.1175/ 2010JPO4315.1.

—_, and —_, 2011: Global energy conversion rate from geostrophic flows into internal lee waves in the deep ocean. Geophys. Res. Lett., 38, L08610, https://doi.org/10.1029/ 2011 GL046576.

— , G. K. Vallis, and A. Adcroft, 2013: Routes to energy dissipation for geostrophic flows in the Southern Ocean. Nat. Geosci., 6, 48-51, https://doi.org/10.1038/ngeo1657.

—, R. Ferrari, N. Grisouard, and K. Polzin, 2014: The impact of finite-amplitude bottom topography on internal-wave generation in the Southern Ocean. J. Phys. Oceanogr., 44, 29382950, https://doi.org/10.1175/JPO-D-13-0201.1.

Plougonven, R., and F. Zhang, 2014: Internal gravity waves from atmospheric jets and fronts. Rev. Geophys., 52, 33-76, https:// doi.org/10.1002/2012RG000419.

Polzin, K. L., 2010: Mesoscale eddy-internal wave coupling. Part II: Energetics and results from PolyMode. J. Phys. Oceanogr., 40, 789-801, https://doi.org/10.1175/2009JPO4039.1.

__, J. M. Toole, and R. W. Schmitt, 1995: Finescale parameterization of turbulent dissipation. J. Phys. Oceanogr., 25, 306-328, https://doi.org/10.1175/1520-0485(1995)025<0306: FPOTD $>2.0 . \mathrm{CO} ; 2$.

Rhines, P., 1970: Edge-, bottom- and Rossby waves in a rotating stratified fluid. Geophys. Astrophys. Fluid Dyn., 1, 273-302, https://doi.org/10.1080/03091927009365776.

Scinocca, J., and N. McFarlane, 2000: The parameterization of drag induced by stratified flow over anisotropic orography. Quart. J. Roy. Meteor. Soc., 126, 2353-2393, https://doi.org/10.1002/ qj. 49712656802 .
Scott, R. B., and Y. Xu, 2009: An update on the wind power input to the surface geostrophic flow of the world ocean. Deep-Sea Res. I, 56, 295-304, https://doi.org/10.1016/j.dsr.2008.09.010.

_ - J. A. Goff, A. C. Naveira Garabato, and A. J. G. Nurser, 2011: Global rate and spectral characteristics of internal gravity wave generation by geostrophic flow over topography. J. Geophys. Res., 116, C09029, https://doi.org/10.1029/ 2011JC007005.

Sen, A., R. B. Scott, and B. K. Arbic, 2008: Global energy dissipation rate of deep-ocean low-frequency flows by quadratic bottom-boundary-layer drag: Computations from currentmeter data. Geophys. Res. Lett., 35, L09606, https://doi.org/ 10.1029/2008GL033407.

Shakespeare, C. J., 2019: Spontaneous generation of internal waves. Phys. Today, 72, 34-39, https://doi.org/10.1063/PT.3.4225.

_ geostrophic adjustment and frontogenesis: Uniform potential vorticity. J. Fluid Mech., 736, 366-413, https://doi.org/10.1017/ jfm.2013.526.

- and - 2014: The spontaneous generation of inertiagravity waves during frontogenesis forced by large strain: Theory. J. Fluid Mech., 757, 817-853, https://doi.org/10.1017/ jfm.2014.514.

$\longrightarrow$, and - , 2015: The spontaneous generation of inertiagravity waves during frontogenesis forced by large strain: Numerical solutions. J. Fluid Mech., 772, 508-534, https:// doi.org/10.1017/jfm.2015.197.

_ and interior amplification of internal waves in a regional-scale ocean model. J. Phys. Oceanogr., 47, 811-826, https://doi.org/ 10.1175/JPO-D-16-0188.1.

Sheen, K. L., and Coauthors, 2013: Rates and mechanisms of turbulent dissipation and mixing in the Southern Ocean: Results from the Diapycnal and Isopycnal Mixing Experiment in the Southern Ocean (DIMES). J. Geophys. Res. Oceans, 118, 2774-2792, https://doi.org/10.1002/jgrc.20217.

Smith, W. H. F., and D. T. Sandwell, 1997: Global seafloor topography from satellite altimetry and ship depth soundings. Science, 277, 1956-1962, https://doi.org/10.1126/science.277.5334.1956.

St. Laurent, L. S., A. C. Naveira Garabato, J. R. Ledwell, A. M. Thurnherr, J. M. Toole, and A. J. Watson, 2012: Turbulence and diapycnal mixing in Drake Passage. J. Phys. Oceanogr., 42, 2143-2152, https://doi.org/10.1175/JPO-D-12-027.1.

Takahashi, A., and T. Hibiya, 2019: Assessment of finescale parameterizations of deep-ocean mixing in the presence of geostrophic current shear: Results of microstructure measurements in the Antarctic Circumpolar Current region. J. Geophys. Res. Oceans, 124, 135-153, https://doi.org/10.1029/ 2018JC014030.

Trossman, D. S., S. Waterman, K. L. Polzin, B. K. Arbic, S. T. Garner, A. C. Naveira Garabato, and K. L. Sheen, 2015: Internal lee-wave closures: Parameter sensitivity and comparison to observations. J. Geophys. Res. Oceans, 120, 7997-8019, https://doi.org/10.1002/2015JC010892.

_- , B. K. Arbic, J. G. Richman, S. T. Garner, S. R. Jayne, and A. J. Wallcraft, 2016: Impact of topographic internal lee-wave drag on an eddying global ocean model. Ocean Modell., 97, 109-128, https://doi.org/10.1016/ j.ocemod.2015.10.013.

von Storch, J.-S., H. Sasaki, and J. Marotzke, 2007: Wind-generated power input to the deep ocean: An estimate using a $1 / 10^{\circ}$ general circulation model. J. Phys. Oceanogr., 37, 657-672, https://doi.org/10.1175/JPO3001.1. 
Waterman, S., K. L. Polzin, and A. C. Naveira Garabato, 2013: Internal waves and turbulence in the Antarctic Circumpolar Current. J. Phys. Oceanogr., 43, 259-282, https://doi.org/ 10.1175/JPO-D-11-0194.1.

,,,--- K. L. Sheen, and A. Forryan, 2014: Suppression of internal-wave breaking in the Antarctic Circumpolar Current near topography. J. Phys. Oceanogr., 44, 1466-1492, https:// doi.org/10.1175/JPO-D-12-0154.1.

Whalen, C. B., L. D. Talley, and J. A. MacKinnon, 2012: Spatial and temporal variability of global ocean mixing inferred from ARGO profiles. Geophys. Res. Lett., 39, L18612, https:// doi.org/10.1029/2012GL053196.

Wright, C. J., R. B. Scott, P. Ailliot, and D. Furnival, 2014: Leewave generation rates in the deep ocean. Geophys. Res. Lett., 41, 2434-2440, https://doi.org/10.1002/2013GL059087.

Wu, L., Z. Jing, S. Riser, and M. Visbeck, 2011: Seasonal and spatial variations of Southern Ocean diapycnal mixing from
ARGO profiling floats. Nat. Geosci., 4, 363-366, https:// doi.org/10.1038/ngeo1156.

Wunsch, C., 1998: The work done by the wind on the oceanic general circulation. J. Phys. Oceanogr., 28, 2332-2339, https://doi.org/ 10.1175/1520-0485(1998)028<2332:TWDBTW >2.0.CO;2.

Yang, L., M. Nikurashin, A. M. Hogg, and B. M. Sloyan, 2018: Energy loss from transient eddies due to lee-wave generation in the Southern Ocean. J. Phys. Oceanogr., 48, 2867-2885, https://doi.org/10.1175/JPO-D-18-0077.1.

,,- H. Sasaki, H. Sun, and J. Tian, 2019: Dissipation of mesoscale eddies and its contribution to mixing in the northern South China Sea. Sci. Rep., 556, https://doi.org/10.1038/ s41598-018-36610-x.

Zheng, K., and M. Nikurashin, 2019: Downstream propagation and remote dissipation of internal waves in the Southern Ocean. J. Phys. Oceanogr., 49, 1873-1887, https://doi.org/ 10.1175/JPO-D-18-0134.1. 